\title{
In-situ Nitrous Acid Generation over Silica Imidazole Catalyst for Dyes Production
}

\author{
Kasim Mohammed Hello*, Nahla Ghaze Fahad \\ Chemistry Department, College of Science, Al-Muthanna University, Iraq
}

Received: 3rd May 2018; Revised: $5^{\text {th }}$ November 2018; Accepted: $9^{\text {th }}$ November 2018; Available online: 30th April 2019; Published regularly: 1't August 2019

\begin{abstract}
The objective of this research is to prepare a new type of heterogeneous catalyst and to study its usage for in-situ nitrous acid generation to form a diazonium salt. The high pure silica ( $>95 \%)$ was produced by burning the clean rice husk at $800^{\circ} \mathrm{C}$. After that, the silica was transferred to sodium silicate using $1.0 \mathrm{M}$ of $\mathrm{NaOH}$, followed by immobilizing with 3-(chloropropyl)triethoxysilane in a simple one-pot synthesis. Finally, the material was refluxed with $(0.015 \mathrm{~mol})$ of $\mathrm{p}$-xylyl di-imidazolium chloride. The silicon solid-state nuclear magnetic resonance shows the $\mathrm{Q}^{4}, \mathrm{Q}^{3}, \mathrm{~T}^{3}$, and $\mathrm{T}^{2}$ chemical shifts at expected position. Carbon solid-state nuclear magnetic resonance spectrum shows different peaks at different chemical shifts related to the carbon structures of the organic moieties. The catalyst is stable up to 277 ${ }^{\circ} \mathrm{C}$ according to the thermal analysis. TEM images show smooth and porous regularly shaped particles with an estimation size of ca. $5 \mathrm{~nm}$. Coupling reaction of aromatic compounds was carried out with a diazonium salt of aniline to yield a monoazo dye. All dyes were showed matching the elemental analysis with the theoretical calculation. Besides this, the spectrum of FT-IR and UV-Visible were recorded. The catalyst was stable, easy separation from the reaction mixture, and reusable by a simple experimental procedure. The catalyst could be used successfully for the nitrous acid generation. Copyright $\mathbb{C}$ 2019 BCREC Group. All rights reserved
\end{abstract}

Keywords: Surface modification; Rice husk ash; Diazotization; Imidazole; Azo dyes; Coupling reaction

How to Cite: Hello, K.M., Fahad, N.G. (2019). In-situ Nitrous Acid Generation over Silica Imidazole Catalyst for Dyes Production. Bulletin of Chemical Reaction Engineering \& Catalysis, 14 (2): 247-259 (doi:10.9767/bcrec.14.2.2617.247-259)

Permalink/DOI: https://doi.org/10.9767/bcrec.14.2.2617.247-259

\section{Introduction}

Diazotization reactions normally prepared via the reaction of primary aromatic amines, aniline, and its related derivatives, with nitrous acid to form a diazonium salt. The formed diazonium salts were capable to couple with organic azobenzene molecules yielding azo dyes. Besides dyes preparation, aromatic diazonium salts can

*Corresponding Author.

Email: kasimhello@gmail.com, kasimhillo@mu.edu.iq (M.H. Kasim), Telp. +9647801274886 also be reached by different procedures to give different materials for various purposes such as sensor [1], carbon nanotube [2], polymer [3], and waste by-products treatment [4], which are relevant to many fields of life such medicine, industry, environment, etc. Numerous methods / techniques, for preparation of diazonium salt, required homogeneous acid as a catalyst. Normally concentrated $\mathrm{HCl}$ or $\mathrm{H}_{2} \mathrm{SO}_{4}$ was used as a homogeneous catalyst in the synthesis of diazonium salt at low temperature [5,6]. The environmental incompatibility is the main limitation of such catalysts. Simultaneously, the production 
of diazonium salts without using homogeneous concentrated acids did not mention in the literature.

Recently, diazotization reactions of various aromatic compounds in aqueous acidic phase, such as: hydrochloric acid under mild conditions, were taken place over the new silica immobilized with nano nitrite [7]. During the use of homogeneous catalysts, the main challenging problem could be the productions of azo dyes over silica in a heterogeneous phase catalyst. Additionally, there is no clean method for production of azo dyes support the green chemistry. Consequently, this work proposing a new type of heterogeneous catalyst to achieve a greener synthetic alternative, due to the increase of interest in the catalysis greener synthetic for dyes production. The heterogeneous catalyst, synthesized in this study, is by utilizing rice husk $(\mathrm{RH})$ as a source of silica. The high pure silica was produced by burning the $\mathrm{RH}$ at a high temperature. As a result of severe conditions, silica was transferred to sodium silicate followed by immobilizing with alkyl silylating agents in a simple one-pot synthesis [8]. Finally, the material was treated with $p$-xylylene di-imidazolium chloride to form a heterogeneous catalyst which was used successfully to generate diazonium salt for azo dyes production.

\section{Materials and Method}

\subsection{Chemicals}

The reagents were imidazole (SigmaAldrich, 98.0\%), sodium hydroxide (Systerm, 99.0\%), nitric acid (Systerm, 65.0\%), 3-(chloropropyl) triethoxysilane (CPTES) (SigmaAldrich, 99\%), benzene (Merck, 99\%), dioxane (Riedel-De Haen, 99.5\%), acetone (Sigma, 98\%), p-xylylene dichloride (Sigma, 98\%), ethyl alcohol (HmbG Chemical, 99.7\%), aniline (SigmaAldrich, 99\%), $\alpha$-naphthol and N,N-dimethyl benzaldehyde (Sigma-Aldrich, 99\%), diethyl ether (GCC, 99\%), potassium carbonate (Sigma-Aldrich, 99\%), $p$-bromobenzaldehyde (Sigma-Aldrich, 99\%), and dichloromethane (Sigma-Aldrich, 99\%). The rice husk (RH) was collected from the rice mill in Samawah city, south of Iraq.

\subsection{Materials Synthesis}

\subsubsection{Synthesis of $p$-xylyl bisimidazole (bis-imi)}

A solution of $p$-xylylene dichloride (1.22 g, $7.0 \mathrm{mmol})$ and imidazole $(1.25 \mathrm{~g}, 18.0 \mathrm{mmol})$ was refluxed at $\left(70-80{ }^{\circ} \mathrm{C}\right)$ in ethanol $(30 \mathrm{~mL})$ for $24 \mathrm{~h}$. The product was washed with diethyl ether then dissolved in potassium carbonate $\left(\mathrm{K}_{2} \mathrm{CO}_{3}\right)$ solution $(6 \%, 30 \mathrm{~mL})$. After standing for 3 days, a white solid precipitated separated out from the solution. This solid was collected and recrystallized from water that produced white crystals. The yield was $1.61 \mathrm{~g}$ (97.0\%), m.p.: $153-154{ }^{\circ} \mathrm{C} .{ }^{1} \mathrm{H}$ NMR $\left(400 \mathrm{MHz}, d_{3^{-}}\right.$ $\left.\mathrm{CD}_{3} \mathrm{CN}\right): \delta 5.1\left(\mathrm{~s}, 4 \mathrm{H}, 2 \times \mathrm{CH}_{2}\right), 6.9(2 \mathrm{H}, \mathrm{d}, 2 \times$ imidazolium H5), $7.2(2 \mathrm{H}, \mathrm{d}, 2 \times$ imidazolium H4'), 7.4 (d, 4H, ArH), 7.7 (s, 2H, $2 \times$ imidazolium H2'); ${ }^{13} \mathrm{C}$ NMR (400MHz, $\left.d_{3}-\mathrm{CD}_{3} \mathrm{CN}\right): \delta 49.9$ $\left(\mathrm{CH}_{2}\right.$ ), 120.3 (imidazolium $\mathrm{C} 4, \mathrm{C} 5, \mathrm{C} 4{ }^{\prime}$ \& $\mathrm{C}^{\prime}$ ), $128.6(4 \times \mathrm{ArC}), 129.6(2 \times \mathrm{ArC}), 138.1,138.2$ (imidazolium $\mathrm{C} 2$ and $\mathrm{C} 2$ '). Elemental analysis (CHNS): Analytical calculation for $\mathrm{C}_{14} \mathrm{H}_{14} \mathrm{~N}_{4}$ : (C, 70.57, H, 5.2, N, 23.51) \%. Experimental: (C, 70.06, H, 5.1, N, 23.74) \%.

\subsubsection{Catalyst preparation, RHAPrIM}

Rice husk was converted to rice husk ash (RHA) and subsequently immobilized with CPTES to produced solid product donated as RHACCl by following the method published in reference [8]. In general, bis-imi (2.0 g, 0.015 mol) was mixed with $(2.0 \mathrm{~g})$ of $\mathrm{RHACCl}$ in 30 $\mathrm{mL}$ of dry toluene. After that, the mixture transferred to an oil bath and then refluxed at $110^{\circ} \mathrm{C}$. After $24 \mathrm{~h}$ of reflux, the reaction mixture was filtered. The solid products washed with three different solvents (toluene, dichloromethane, and ethanol) to remove the unreacted organic. The product was transferred to the oven for drying at $100{ }^{\circ} \mathrm{C}$ for $24 \mathrm{~h}$. About $1.80 \mathrm{gm}$ was yield from applied this method.

\subsection{Catalyst Activity}

$100 \mathrm{mg}$ of RHAPrIM were mixed with 1.0 $\mathrm{mL}(10 \mathrm{mmol})$ of aniline which was soluble in 5 $\mathrm{mL}$ of distilled water. About $0.69 \mathrm{~g}(10 \mathrm{mmol})$ of sodium nitrite was dissolved in $5 \mathrm{~mL}$ of distilled water then added to the catalyst-aniline mixture very slowly and stirring for $24 \mathrm{~h}$, while the temperature never goes above $15{ }^{\circ} \mathrm{C}$. Thereafter, the catalyst was removed by filtrating about $250 \mathrm{mg}$ of resorcinol which was dissolved in $2.0 \mathrm{~mL}$ of $10 \% \mathrm{NaOH}$ and then 5.0 $\mathrm{mL}$ distilled water was added. The mixture color was changed directly which indicated to the end point of the reaction. As the reactants and the product are solid phase, the calculation of yield (conversion) was done by dividing the experimental weight $\left(W t_{e x}\right)$ on the theoretical weight ( $W t_{\text {theo }}$ ) multiplying by $100 \%$ as shown in the formula below (Equation (1)).

Yield $\%=\left(W t_{\text {ex }} / W t_{\text {theo }}\right) \times 100 \%$ 


\subsection{Sample Characterization}

2.4.1 Elemental analysis and nitrogen adsorption desorption

The percentage of each carbon, hydrogen, and nitrogen was determined by CHN analyzer (Perkin Elmer-2400). Surface parameters were analyzed by physical adsorption of nitrogen in automatic physisorption porosimeter (Autosorb-1 CLP, Quantachrom, USA).

\subsubsection{X-ray diffraction patterns (XRD)}

The powder XRD of the sample was done on a Siemens diffractometer, D5000, Kristalloflex. The diffraction angle was scanned for $2 \mathrm{~h}$ at a rate in $6.0^{\circ} . \mathrm{min}^{-1}$.



Scheme 1. The synthesis of 1,4-bis(imidazole-1ylmethyl)benzene (Bis-Imi)

\subsubsection{FT-IR spectroscopy}

The FT-IR spectra were obtained using Shimadzu 8400 s spectrophotometer. A $0.5 \mathrm{mg}$ of $\mathrm{KBr}$ to the $0.1 \mathrm{mg}$ of sample was taken and grained to make the $\mathrm{KBr}$ discs.

2.4.4 Thermogravimetric analysis TGA / Differential thermal analysis DTA

TGA/DTA was performed using a dualpurpose instrument type Perkin Elmer TGA4000; about $10.0 \mathrm{mg}$ of sample was heated from $40{ }^{\circ} \mathrm{C}$ to $900{ }^{\circ} \mathrm{C}$ at $20^{\circ} \mathrm{C} / \mathrm{min}$ under nitrogen flow.

\subsection{5 ${ }^{29} \mathrm{Si}$ and ${ }^{13} \mathrm{C}$ MAS NMR}

The ${ }^{29} \mathrm{Si}$ and ${ }^{13} \mathrm{C}$ MAS NMR were recorded by using Bruker machine type (DSX-300) was used to obtained ${ }^{29} \mathrm{Si}$ and ${ }^{13} \mathrm{C}$ MAS NMR.

\subsubsection{TEM and SEM micrographs}

The SEM images were carried out using Leica Cambridge S360 machine. The machine was provided with EDX type Falcon System. While the TEM images were deducted by Philips CM12 equipment. In general the sample was suspended in absolute ethanol and

$$
\mathrm{RHA}+\mathrm{NaOH} \underset{\mathrm{RT} / 30 \mathrm{~min}}{\longrightarrow} \text { Sodium silicate }
$$


Scheme 2. The reaction sequence and the possible structures for RHAPrIM as suggested by different techniques. 
then droplet on carbon film coated with 400 mesh copper grid and left for 1-3 min.

\section{Results and Discussion}

\subsection{Synthesis of Bis-Imi}

Formation of bis-imi basically depends on the replacement of chloride in $p$-xylylene dichloride with imidazole in dioxane under refluxed condition Scheme 1 . The ${ }^{1 \mathrm{H}}$ and ${ }^{13} \mathrm{C}$ NMR spectra and elemental analysis $(\mathrm{CHN})$ are nicely monitored the successful formation of the bis-Imi. ${ }^{1} \mathrm{H}$ NMR spectrum of bis-imi in Figure 1(a) shows the presence of imidazolium proton $\mathrm{H} 2$ ' signal $(\mathrm{N}-\mathrm{CH}-\mathrm{N})$ at chemical shifts of $7.7 \mathrm{ppm}$. This chemical shift is consistent with the chemical shifts of common imidazolium salts [9]. The carbene carbon resonances of imidazole (C2, C2') led to downfield signals at $\delta$ of 138.2 and $138.1 \mathrm{ppm}$, respectively (Figure 1(b)). Aromatic carbons (i) and (i-) are observed at 129.55 and $129.6 \mathrm{ppm}$, while other chemical shifts of aromatic carbons, (ii), (ii-), are observed at 128.6 and $129.01 \mathrm{ppm}$, the car-

(a)

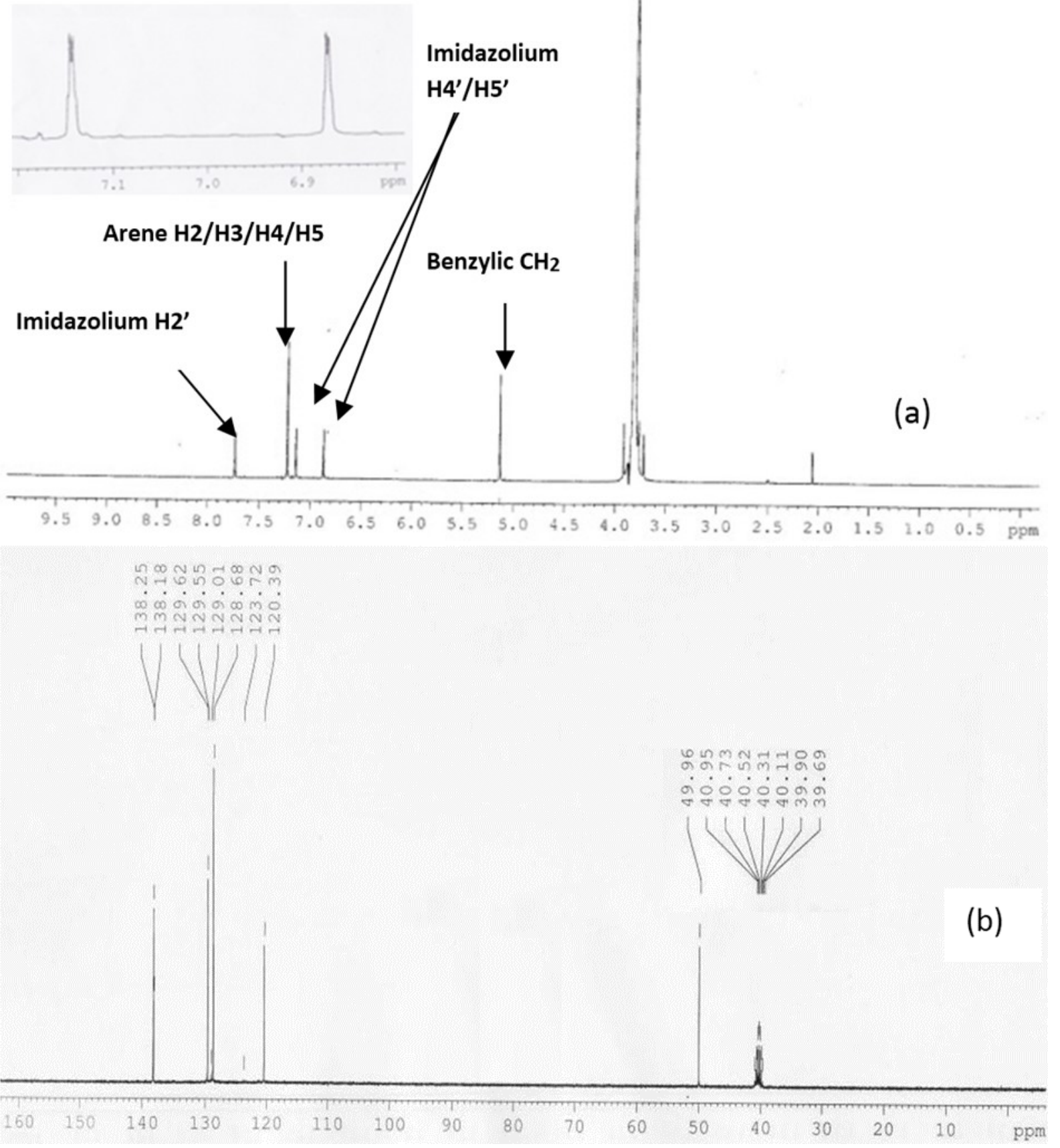

Figure 1. The NMR spectrum of bis-imi in d3-CD3CN. (a) ${ }^{1} \mathrm{H}$ NMR, (b) ${ }^{13} \mathrm{CNMR}$. 
bons of $\mathrm{C} 3, \mathrm{C} 4, \mathrm{C} 3{ }^{\prime}$, and $\mathrm{C} 4{ }^{\prime}$ are observed at $120.3 \mathrm{ppm}$. Methylene group's $\left(\mathrm{CH}_{2}\right)$ is shown at chemical shift $49.9 \mathrm{ppm}$. It is also found that the experimental elemental analysis of the synthesis bis-imi is in agreement well with calculated one. This data clearly indicates the significant synthesis of the bis-imi.

\subsection{Synthesis of RHAPrIM}

CPTES was necessary for functionalization silica from RHA. The bis-imi immobilization proceeds via proton abstraction from amine group in imidazole and alkyl chloride bonded to silica propyl chain Scheme 2. This reaction is anchored bis-imi to silica via the connection to propyl chain in organosilane. Deep analysis for the prepared catalyst was carried including solid-state NMR, stability, surface area and others as in the subtitle below.

\subsubsection{Elemental analysis}

To monitor the new elements onto silica the elemental data were used by the combination of elemental analysis (CHN) and energy dispersive X-ray analysis (EDX) analysis (shown in bract) Table 1. Elemental analysis percentages

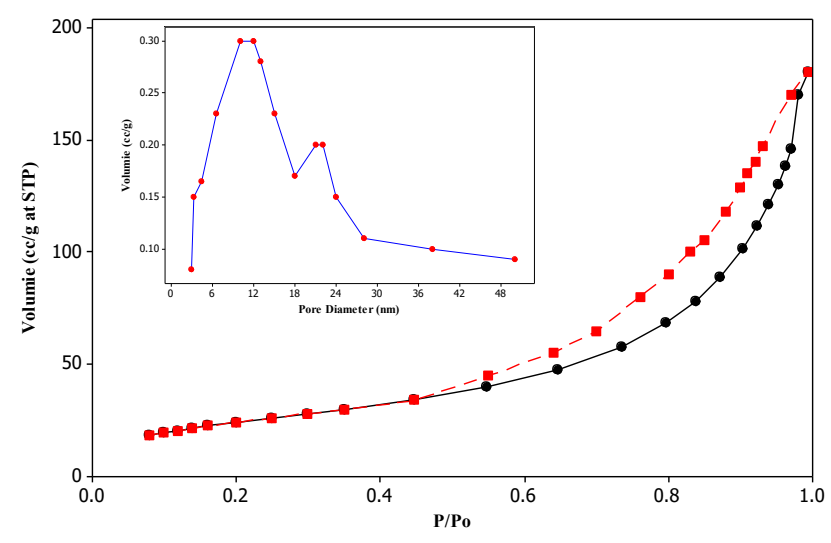

Figure 2. Nitrogen adsorption-desorption isotherms of RHAPrIM with pore size distribution of RHACCl (not shown) showed the $\mathrm{C}$ and $\mathrm{H}$ content are 11.70 and $1.90 \%$, respectively [8]. Carbone content of RHAPrIM 16.74\% (30.22\% according to the EDX) is slightly higher than RHACCl, as a result of immobilization of bisimi. Nitrogen composition showed $1.91 \%$, (3.30\% according to the EDX). The elemental data analysis reflects that the bis-imi is indeed incorporated on the silica.

3.2.2 X-ray diffraction pattern (XRD) and nitrogen adsorption-desorption analysis

An amorphous phase is shown by XRD pattern (not shown) of RHAPrIM due to the presence of broadband at $2 \theta=22^{\circ}$. This result reflects that no change in phases after the immobilization of bis-imi onto silica. In the previous study both of RHA and RHACCl shows amorphous phase $[8,10]$.

The nitrogen adsorption-desorption isotherm and pore size graphs for RHAPrIM are given in Figure 2. According to IUPAC classification, the isotherm is of type IV with $\mathrm{H} 1$ hysteresis loop [11]. The isotherm at $P / P_{o}$ form 0.70-0.85 the adsorption curve shows a sharp elevation. This is due to the presence of uniform size pores. According to the BrunauerEmmett-Teller (BET) method RHAPrIM had $91.16 \mathrm{~m}^{2} . \mathrm{g}^{-1}$ surface areas. This surface area is less that of RHACCl $\left(633 \mathrm{~m}^{2} \cdot \mathrm{g}^{-1}\right)$ [8]. The bisimi ligand has larger molecules and presumably could block the pores and reduces the surface area of RHAPrIM. The RHAPrIM shows two types of pores the first is ranged from 4 to $15 \mathrm{~nm}$ and the second from 18 to $24 \mathrm{~nm}$. Both pores fall in the mesoporous range (Table 1).

\subsubsection{FT-IR spectroscopy}

The spectra of RHACCl and RHAPrIM with the differential of both catalysts are giving in Figure 3. The FT-IR spectra allowed us to observe the bands characteristic of most functional groups of mesoporous RHAPrIM. Our previ-

Table 1. The physical parameters obtained for RHAPrIM. The $\mathrm{C}, \mathrm{H}$, and $\mathrm{N}$ contents determined by a combination of elemental and EDX analysis (shown in bract). The results of Nitrogen adsorptiondesorption analysis are also shown

\begin{tabular}{|c|c|c|c|c|c|c|c|}
\hline \multicolumn{5}{|c|}{ Elemental analysis (\%) } & \multirow{3}{*}{$\begin{array}{c}\text { Specific Surface } \\
\text { area }\left(\mathrm{m}^{2} \cdot \mathrm{g}^{-1}\right) \\
\\
91.16\end{array}$} & \multirow{3}{*}{$\begin{array}{c}\begin{array}{c}\text { Average } \\
\text { pore volume } \\
\left(\mathrm{cm}^{3} \cdot \mathrm{g}^{-1}\right)\end{array} \\
\\
\\
0.24\end{array}$} & \multirow{3}{*}{$\begin{array}{c}\begin{array}{r}\text { Average pore } \\
\text { diameter (nm) }\end{array} \\
10.9\end{array}$} \\
\hline $\mathrm{C}$ & $\mathrm{H}$ & $\mathrm{N}$ & $\mathrm{Cl}$ & $\mathrm{Si}$ & & & \\
\hline $\begin{array}{c}16.74 \\
(30.22)\end{array}$ & $\begin{array}{c}2.34 \\
(-)\end{array}$ & $\begin{array}{c}1.91 \\
(3.30)\end{array}$ & $\begin{array}{c}- \\
(3.8)\end{array}$ & $\begin{array}{c}- \\
(16.69)\end{array}$ & & & \\
\hline
\end{tabular}


ous studies had been described the $\mathrm{Si}-\mathrm{O}-\mathrm{Si}$ vibrations of RHA which appeared at $1101 \mathrm{~cm}^{-1}$ [8]. The vibration is observed to shift to 1082 $\mathrm{cm}^{-1}$ in RHACCl and to $1061 \mathrm{~cm}^{-1}$ in RHAPrIM. Silanol groups $(\mathrm{SiO}-\mathrm{H})$ and absorbed water (HO-H) appeared as a broadband around 3485 $\mathrm{cm}^{-1}[12]$. At $3225 \mathrm{~cm}^{-1}$ in the differential the absorption band corresponds to the imidazole $\mathrm{C} 5-\mathrm{H}$ bond vibration has appeared. Benzene ring identified by vibration of $\mathrm{C}=\mathrm{C}$ stretching at $1566 \mathrm{~cm}^{-1}$. While in the deferential spectrum the vibration at $1618 \mathrm{~cm}^{-1}$ are due to the imine groups, $\mathrm{C}=\mathrm{N}$ and vibration at $1225 \mathrm{~cm}^{-1}$ is due to $\mathrm{Si}-\mathrm{C}$ covalent bond. All these vibrations for the expected functional groups FT-IR refer that bis-im molecules are loaded onto silica via RHACCl.

\subsubsection{The solid state ${ }^{29} \mathrm{Si}$ and ${ }^{13} \mathrm{C}$ NMR}

Our previous study [13] found that the ${ }^{29} \mathrm{Si}$ MAS NMR of RHA which has only the presence of quadrant $\left(\mathrm{Q}^{4}\right)$ and tripartite $\left(\mathrm{Q}^{3}\right)$ at -110 and $-100 \mathrm{ppm}$, respectively. Beside those $\mathrm{Q}^{4}, \mathrm{Q}^{3}$ silicon atom the RHACCl shows $\mathrm{T}^{3}$, and $\mathrm{T}^{2}$ [8]. The values of those chemical shifts are found $-109.9,-100.6,-65.2$, and $-57.4 \mathrm{ppm}$, respectively.

${ }^{29}$ Si MAS NMR spectrum of RHAPrIM has a similar sequence to that onto RHACCl with slight shifts (Figure $4(\mathrm{a})$ ). Q $\mathrm{Q}^{4}, \mathrm{Q}^{3}$ silicon atoms appear at $\delta=-110.9$ and $-100.9 \mathrm{ppm}$. Another chemical shift at $-65.4 \mathrm{ppm}$ is observed indicates the formation of $\mathrm{T}^{3}$, while a chemical shift at $-57.3 \mathrm{ppm}$ indicates the formation of $\mathrm{T}^{2}$. The data from ${ }^{29} \mathrm{Si}$ NMR spectrum reveal that bis-imi molecules are successfully incorpo-

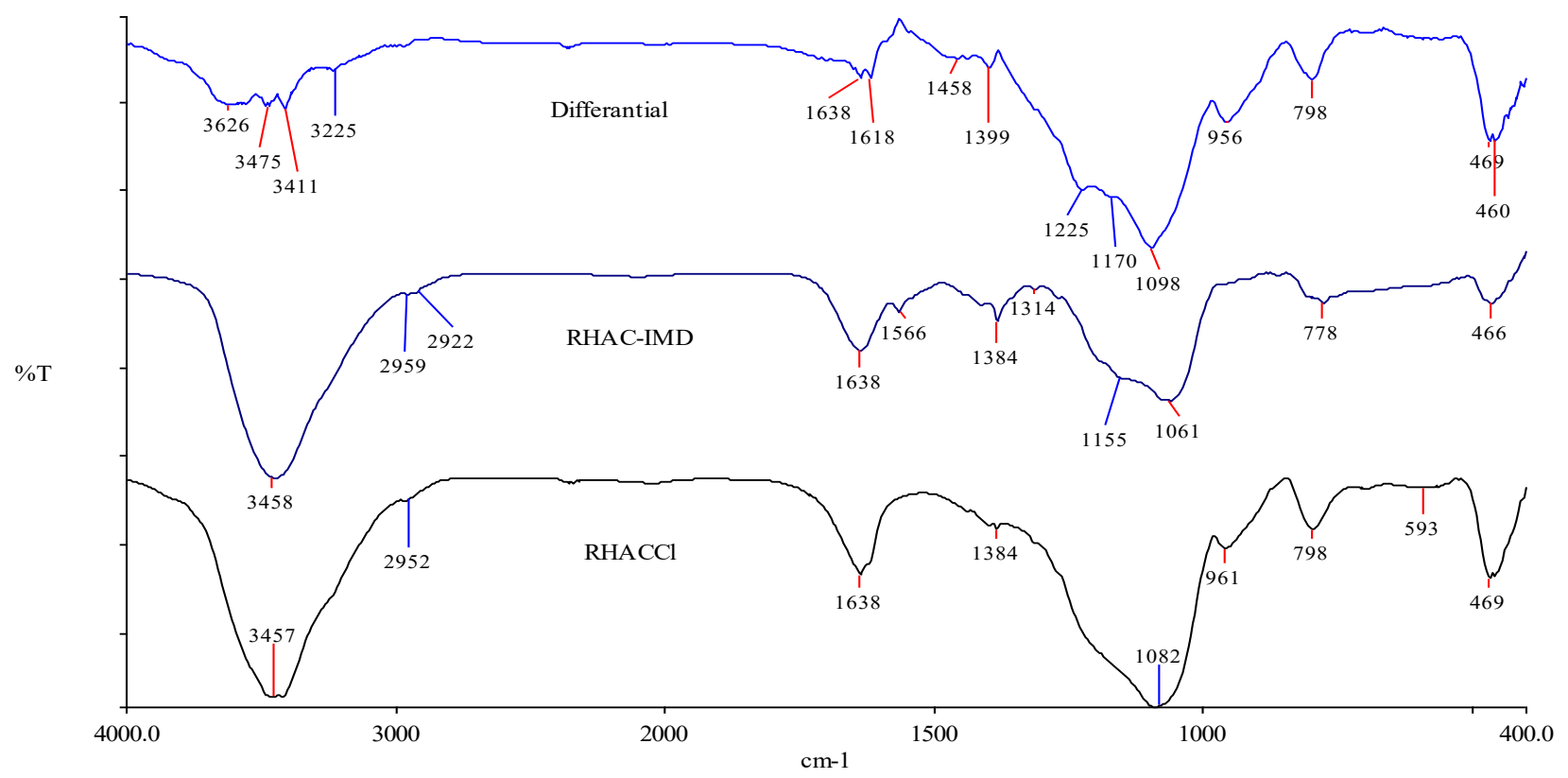

Figure 3. The FT-IR spectra of RHACCl, RHAPrIM and the differential spectrum
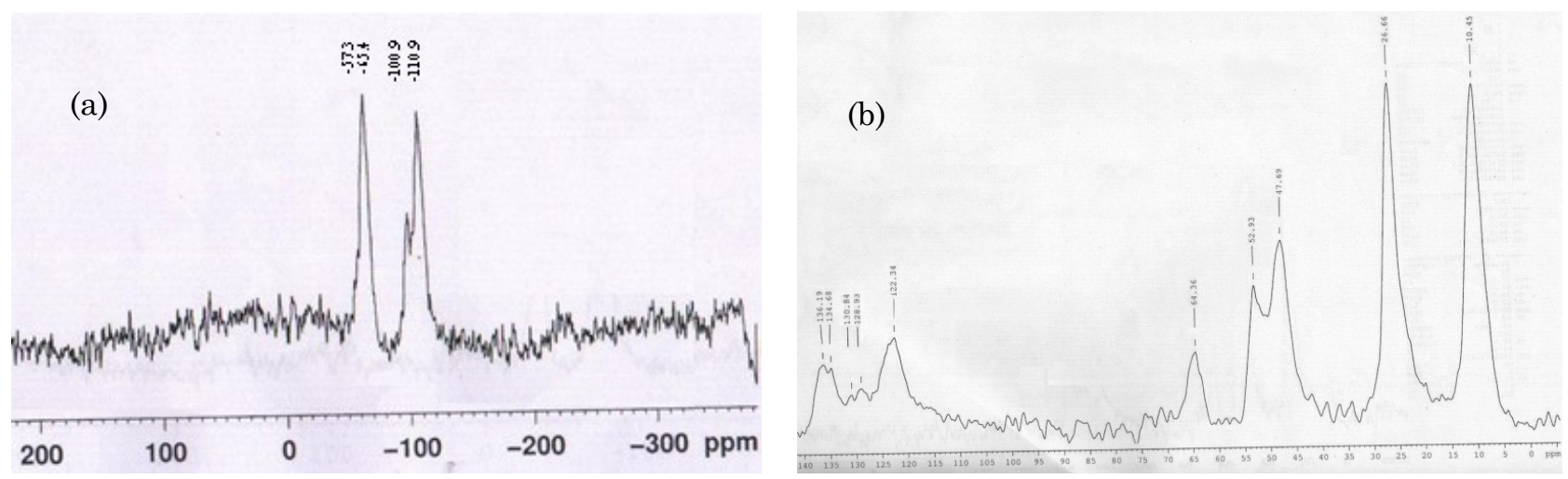

Figure 4. The solid sate NMR spectra of RHAPrIM. (a) The ${ }^{29} \mathrm{Si}$ MAS NMR spectrum (b) The ${ }^{13 \mathrm{C}}$ MAS NMR spectrum 
Bulletin of Chemical Reaction Engineering \& Catalysis, 14 (2), 2019, 253
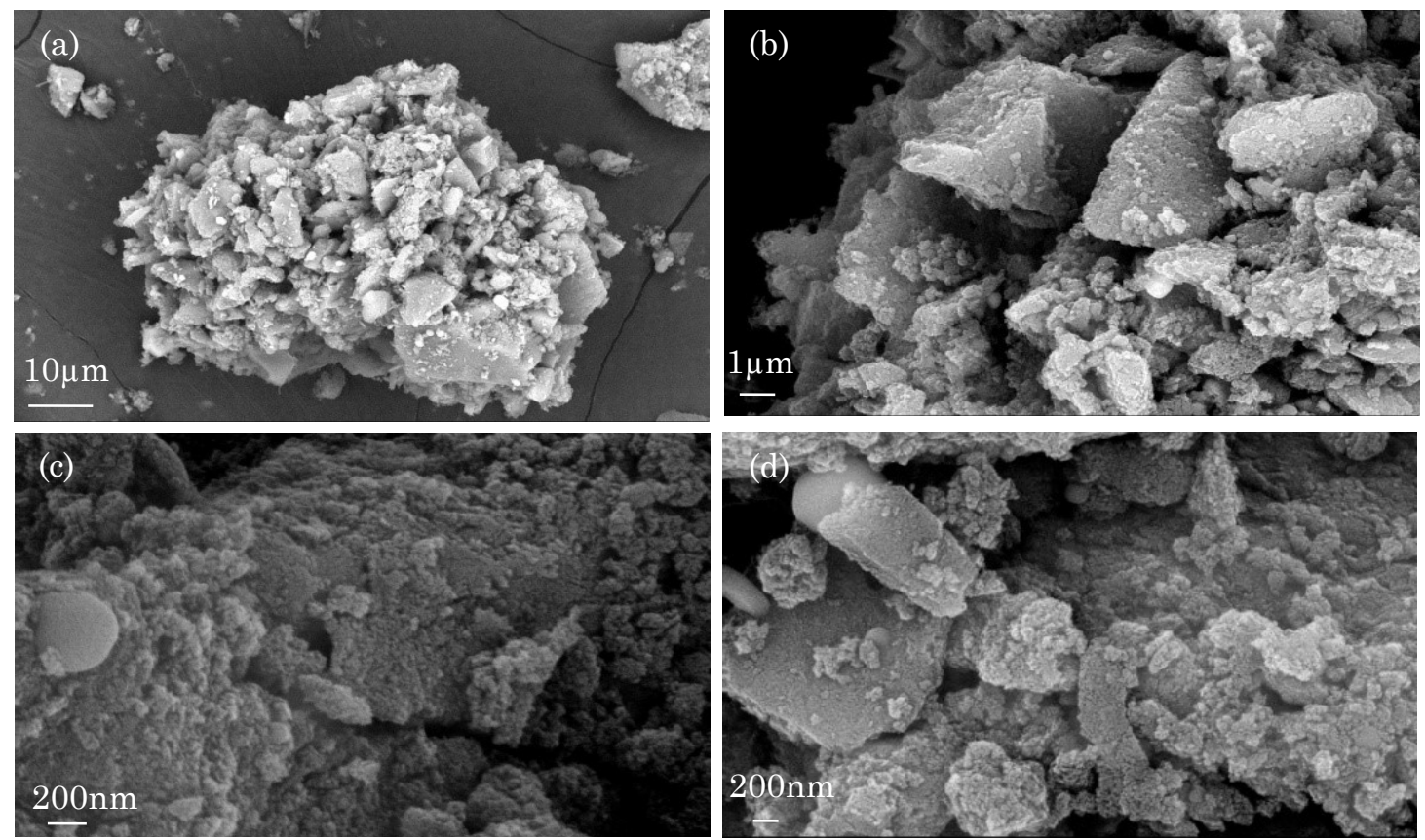

Figure 5. The SEM images RHAPrIM
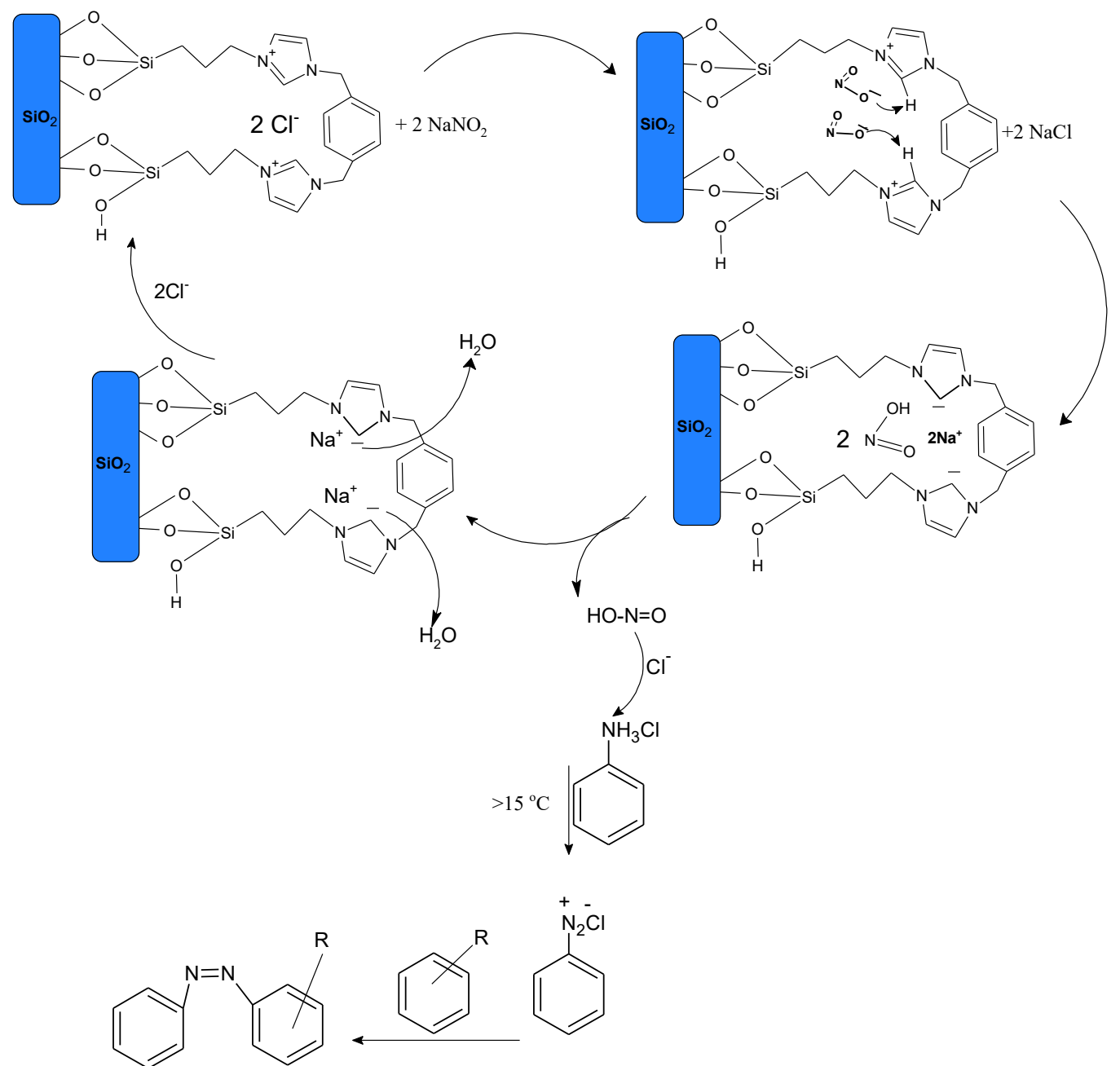

$\mathrm{R}=$ Phenyl, 2-CHO-4-Br, 2-CHO-4-NMe2,

2-OH-4-Me, Naphthol

Scheme 3. The generation of diazonium salt over RHAPrIM

Copyright $\odot$ 2019, BCREC, ISSN 1978-2993 
rated with $\mathrm{RHACCl}$. It is also saved to conclude that RHAPrIM has two type of structures as suggested in Scheme 2.

Figure 4(b) shows the solid-state ${ }^{13} \mathrm{C}$ NMR of RHAPrIM. The carbon bonded to silicon is shown at $10.4 \mathrm{ppm}$ (C1 carbon). At $26.6 \mathrm{ppm}$ the peak is assigned to the $\mathrm{C} 2$ carbon, while the C3 carbon is observed at $47.69 \mathrm{ppm}$. Comparing to the ${ }^{13} \mathrm{C}$ NMR of RHACCl [8] those chemical shifts are downfield shifted. The peaks at 52.9 and $64.3 \mathrm{ppm}$ are corresponding to the two $\mathrm{CH}_{2}$ groups. Imidazole carbons ring $\mathrm{C} 4, \mathrm{C} 5, \mathrm{C} 4$ ', and C5' (Scheme 1) chemically equivalent are shown at $122.3 \mathrm{ppm}$. Benzene ring $(4 \times \mathrm{ArC})$ appears at 128.9 and $130.8 \mathrm{ppm}$. The chemical shift at $135.2 \mathrm{ppm}$ is related to the two aromatic carbons which they bonded to the $\mathrm{CH}_{2}$ groups. The chemical shifts at 134.6 and 136.1 ppm refer to the imidazole carbon atom $\mathrm{C} 2$ and C2' (Scheme 1).

\subsubsection{Electron microscopy study}

The SEM images (Figure 5) show irregular shapes arranged randomly on a smooth surface. No specific geometrical shapes are observed.
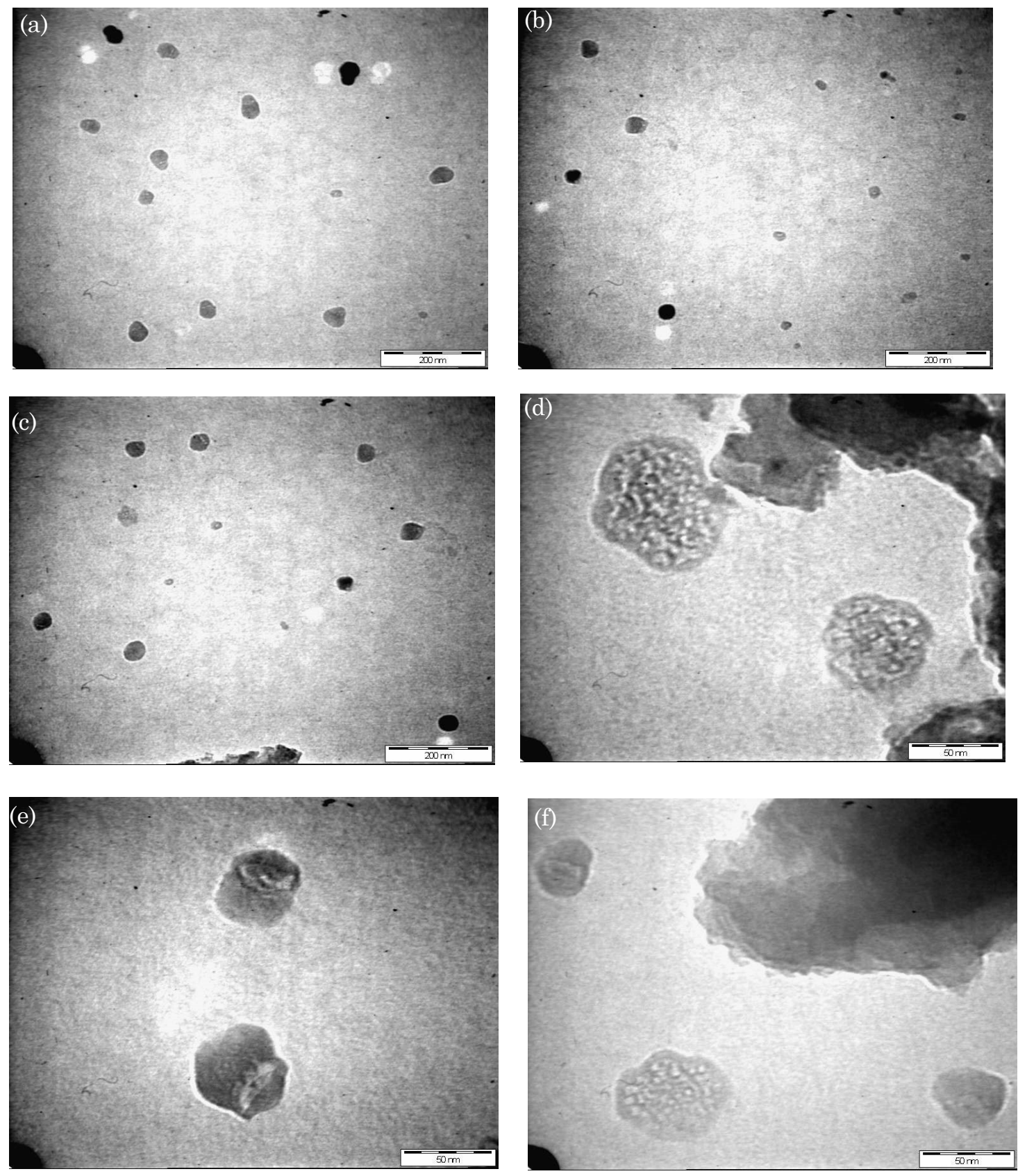

Figure 6. The SEM images for the RHAPrIM at different magnifications 
Figure 6 shows the TEM images of RHAPrIM. Regularly shaped particles of RHAPrIM are observed. The RHAPrIM consists of two types of spherical particles. Both those particles have an approximate size of ca. $5 \mathrm{~nm}$. The first type of particle seems to be smooth in shape, while the second one shows porous shape. The particles sizes are in nano range which might have important characterization besides having a catalyst.

\subsubsection{Thermal analysis TGA/DTA}

TGA/DTA curve of RHAPrIM is shown in Figure 7. Four characteristic decomposition stages are observed. First mass loss of water adsorbed started at $39{ }^{\circ} \mathrm{C}$. Second mass loss (ca. $5.9 \%$ ) at $277^{\circ} \mathrm{C}$, and third mass loss (ca. $7.7 \%$ ) at $344{ }^{\circ} \mathrm{C}$, due to the organic moiety decomposition anchored onto silica. The fourth mass loss (ca. $1.1 \%$ ) at $514{ }^{\circ} \mathrm{C}$, attributed to the formation of siloxane groups as a result of silanol groups condensation.

\subsection{Catalytic Performances}

The catalytic activity of RHAPrIM is examined in-situ preparation of nitrous acid which was used to prepare diazonium salt. In the case of its reaction with aniline, the aniline is first dissolved in water at the presence of RHAPrIM catalyst. To that mixture, a solution of sodium nitrite is added. This reaction produced in-situ nitrous acid which attacks aniline and forming the diazonium salt Scheme 3. After the formation of diazonium salt, simple filtration is necessary to remove the catalyst. The final reaction is a coupling of diazonium salt with resorcinol as a model substrate to produce azo dyes.

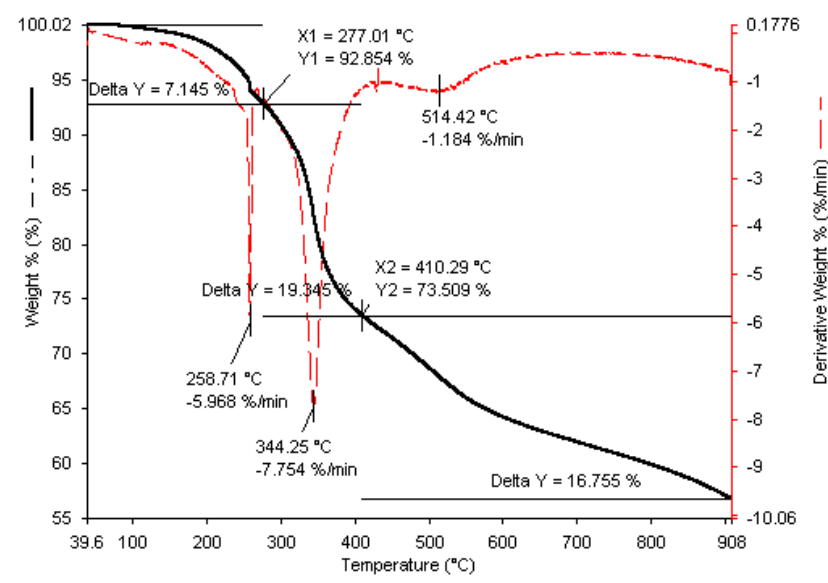

Figure 7. TGA/DTA curve of RHAPrIM

\subsubsection{Optimization of reaction conditions}

The activity of RHAPrIM was analyzed at different masses of catalyst, solvents, and temperatures (Table 2). Coupling reaction of the diazonium salt with resorcinol was a common method to synthesized azo dye. Four different masses of RHAPrIM were used (50, 100, 150, and $250 \mathrm{mg}$ ) to reach the optimum mass of catalyst as shown in Table 2 . The yield reached its maximal 59\% when the reaction is carried out using $100 \mathrm{mg}$ at $0-5{ }^{\circ} \mathrm{C}$. The increases of the catalyst mass to $250 \mathrm{mg}$, however, the yield does not change. At catalyst mass less than $100 \mathrm{mg}$ it was observed that the yield decreased to be $40 \%$. Thus, the $100 \mathrm{mg}$ of catalyst mass is selected to be the optimum.

Temperature is a very important factor in the reaction due to the fact that the sensitivity of nitrous acid, therefore the reaction temperatures were controlled to be not more than 15 ${ }^{\circ} \mathrm{C}$. Clearly found that when the reaction temperature increased from 0 to $10{ }^{\circ} \mathrm{C}$, the yield increased from 59 to $92 \%$ and a temperature of $15{ }^{\circ} \mathrm{C}$ the azo dye yield decrees to be $76 \%$ as shown in Table 2. As the temperature reached $15{ }^{\circ} \mathrm{C}$ the nitrous acid decomposition may be the main reason for the yield decreasing of azo dye.

Solvents effects on the yield of azo dye were studied and the results were listed in Table 2 . The water, ethyl alcohol, and diethyl ether

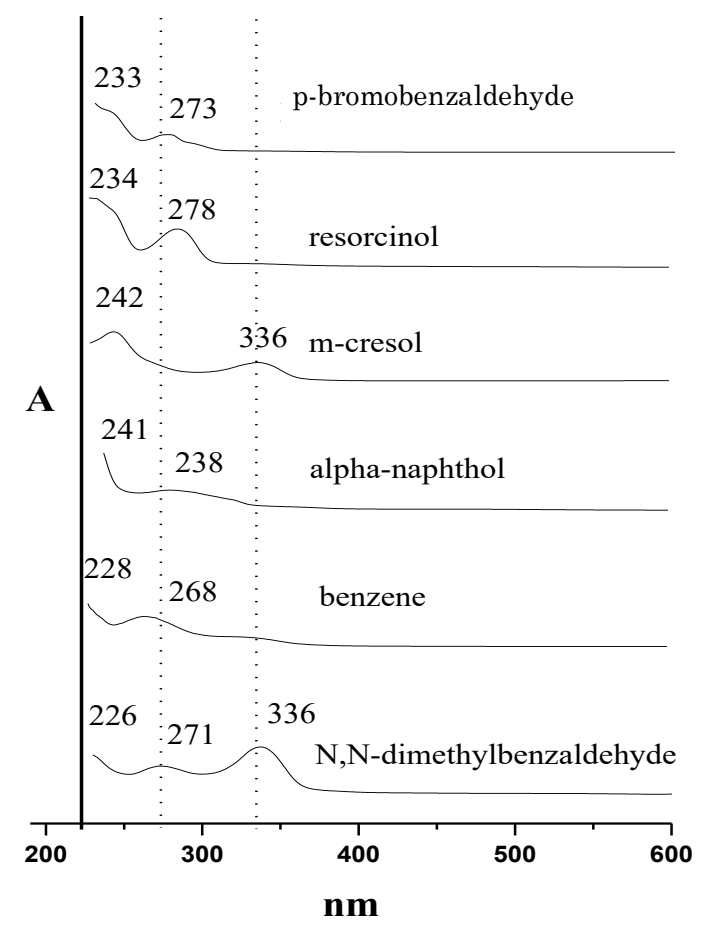

Figure 8. The UV-Vis of the monoazo dyes derivatives prepared over RHAPrIM 
were used as reaction solvents. The structures of those solvents are the main reason behind their used. During the experiment, water is found the best solvent for this reaction with $92 \%$ yield of azo dye. It was found that the yield of azo dye decrease in the medium of ethyl alcohol to reached $61 \%$ and $57 \%$ in diethyl ether. Water is capable to form hydrogen bonding with the reactant over the catalyst surface and this could lead to the high percentage of yield. In case of using diethyl ether, the probability to form a hydrogen bonding became less and the yield could reduce.

After the end of the reaction, RHAPrIM was easily recovered and reused at least two times with minimum loss in activity. It should be noted that the activity is reduced after the third run of the reaction and reached to be 89 $\%$. It was deduced that the RHAPrIM might be poisoning by the solvent used by forming a hy-

Table 2. The effects of different parameters on the production of azo dyes over RHAPrIM catalyst were shown

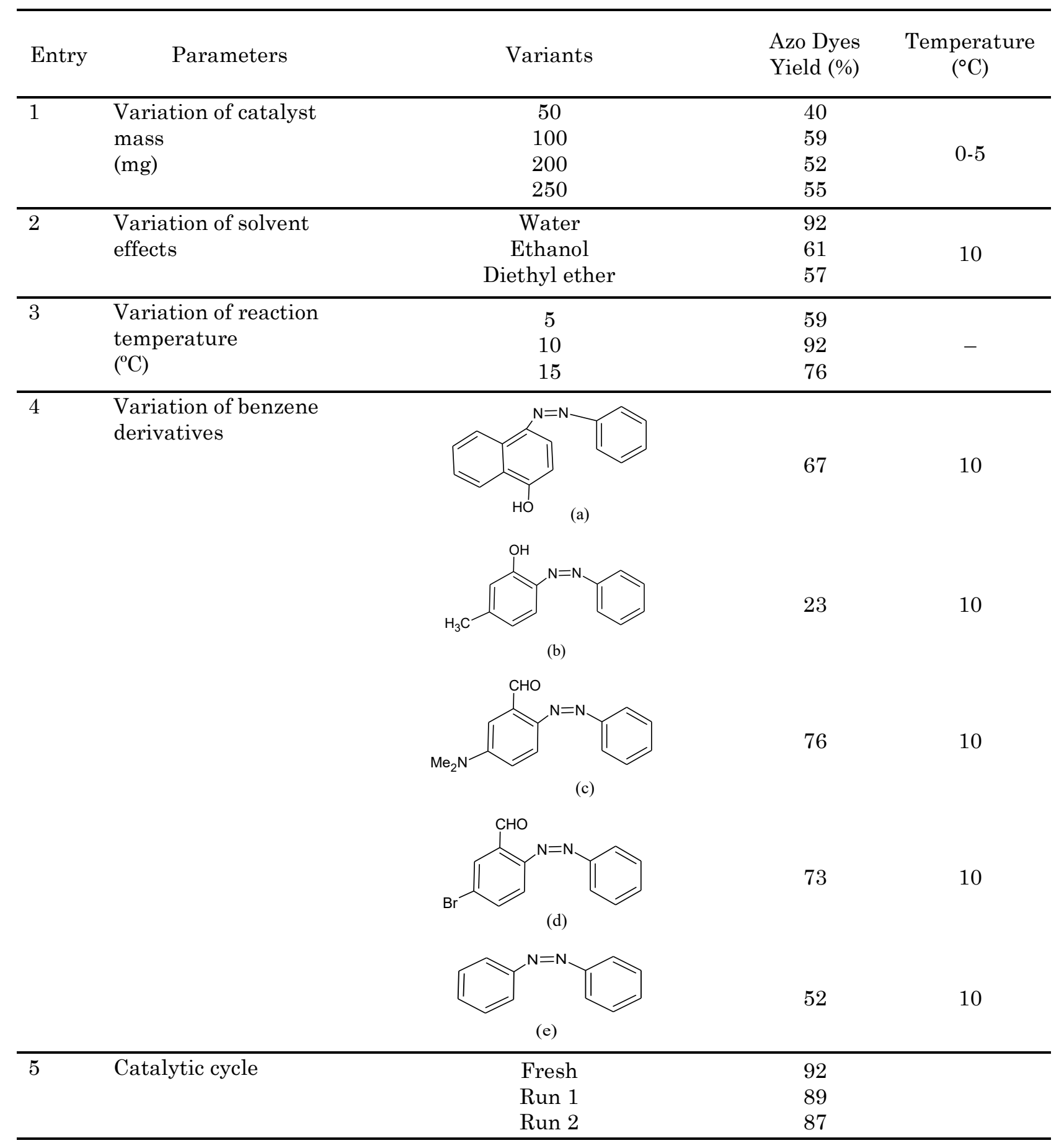




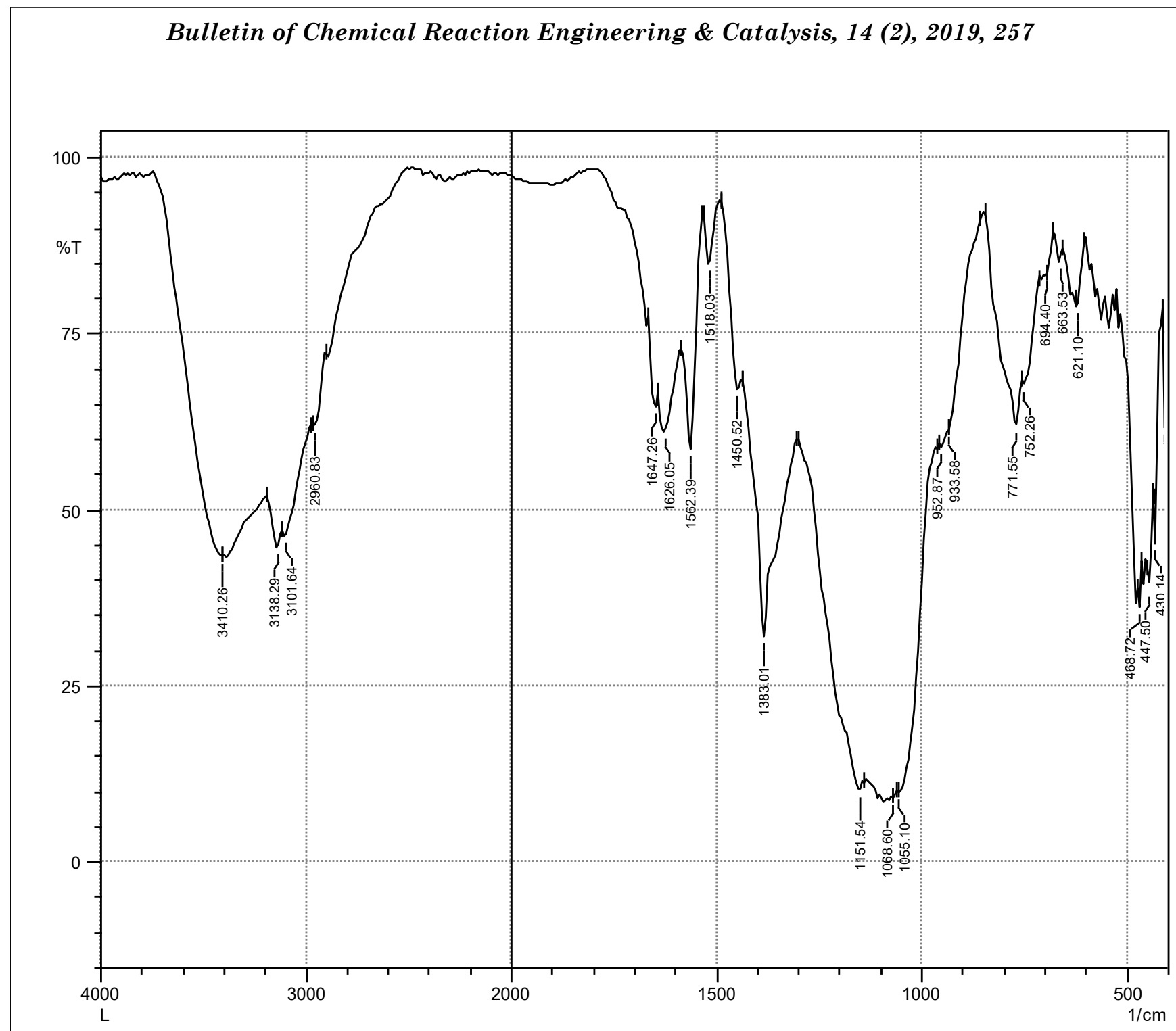

Figure 9. The FT-IR spectrum of RHAPrIM after the second used

Table 3. The physical properties, elemental analysis, and FT-IR of azo dye derivatives prepared over RHAPrIM

\begin{tabular}{|c|c|c|c|c|}
\hline \multirow{2}{*}{ Compound } & \multirow{2}{*}{$\begin{array}{l}\text { m.p } \\
\left({ }^{\circ} \mathrm{C}\right)\end{array}$} & \multicolumn{2}{|c|}{ Elemental analysis (\%) } & \multirow{2}{*}{$\begin{array}{l}\text { FT-IR } \\
\left(\mathrm{cm}^{-1}\right)\end{array}$} \\
\hline & & Calculated & found & \\
\hline a & 122 & $\begin{array}{l}\mathrm{C}: 77.4, \mathrm{H}: 4.87 \\
\mathrm{~N}: 11.28\end{array}$ & $\begin{array}{l}\text { C:77.66, H:5.0, } \\
\quad \mathrm{N}: 11.0\end{array}$ & $\begin{array}{c}3486(\mathrm{O}-\mathrm{H}), 3041 \text { (C-Har), } \\
1578(\mathrm{~N}=\mathrm{N}),\end{array}$ \\
\hline $\mathrm{b}$ & 130 & C:72, H:5; N:10 & $\begin{array}{l}\text { C:71.6, H:5.62; } \\
\text { N:11.28 }\end{array}$ & $\begin{array}{c}3436(\mathrm{O}-\mathrm{H}), 3037(\mathrm{C}-\mathrm{Har}) \\
1577(\mathrm{~N}=\mathrm{N})\end{array}$ \\
\hline $\mathrm{c}$ & 150 & $\mathrm{C}: 71, \mathrm{H}: 5.5 ; \mathrm{N}: 16$ & $\begin{array}{c}\text { C:69.99, H:5.53; } \\
\text { N:12.77 }\end{array}$ & $\begin{array}{c}3060\left(\mathrm{C}-\mathrm{H}_{\mathrm{Ar}}\right), 2950(\mathrm{C}-\mathrm{Hal}) \\
1530(\mathrm{~N}=\mathrm{N}), 1610(\mathrm{C}=\mathrm{O})\end{array}$ \\
\hline$d$ & 115 & $\mathrm{C}: 53, \mathrm{H}: 3 ; \mathrm{N}: 9$ & $\begin{array}{c}\mathrm{C}: 52.76, \mathrm{H}: 2.87 \\
\mathrm{~N}: 8.33\end{array}$ & $\begin{array}{c}3090\left(\mathrm{C}-\mathrm{H}_{\mathrm{Ar}}\right), 1570(\mathrm{~N}=\mathrm{N}) \\
1680(\mathrm{C}=\mathrm{O})\end{array}$ \\
\hline e & 92 & $\begin{array}{c}\mathrm{C}: 78.23 ; \mathrm{H}: 6.57 \\
\mathrm{~N}: 15.21\end{array}$ & $\begin{array}{c}\mathrm{C}: 78.23 ; \mathrm{H}: 6.57 \\
\mathrm{~N}: 15.21\end{array}$ & $3100\left(\mathrm{C}-\mathrm{H}_{\mathrm{Ar}}\right), 1510(\mathrm{~N}=\mathrm{N})$ \\
\hline
\end{tabular}


drogen bonding with the solvent and this could block the pore of the catalyst. The hydrogen bonding was formed between the reactants and the solvent over the catalyst active center. Beside this, a hydrogen bonding could also be formed between the active centers and the solvent (in case of using water). The TGA shows that the catalyst is able to capture the moisture from the air (about $5.9 \%$ of water for each 10 $\mathrm{mg}$ of catalyst was deducted). This phenomena clearly shows that the catalyst surface is highly hydrophilic. This will be decried in the other solvent of ethanol which has one hydroxyl groups able to form hydrogen bonding, and less in diethyl ether (which has not any hydroxyl groups). Therefore there is no deactivation of the catalyst in case of using diethyl ether and ethanol. After the catalyst used, a TGA/DTA was running and the result has shown that the moisture became (12.1\%) which clearly supported that the poisoning of the catalyst by the solvent which may explain the minimum reducing of the activity after the thread run.

\subsubsection{Proposed mechanism}

A mineral acid is usually used to generate the nitrous acid by acidification of aqueous solutions sodium nitrite. The RHAPrIM has imidazole acidic hydrogen able to acidification of sodium nitrite in situ. Free nitrous acid is liberated and attack aniline rapidly to form the diazonium salt. The formed diazonium salt is able to couple with an aromatic molecule to produced azo dyes, while the fresh catalyst is continued for catalyzing new reaction as in Scheme 3.

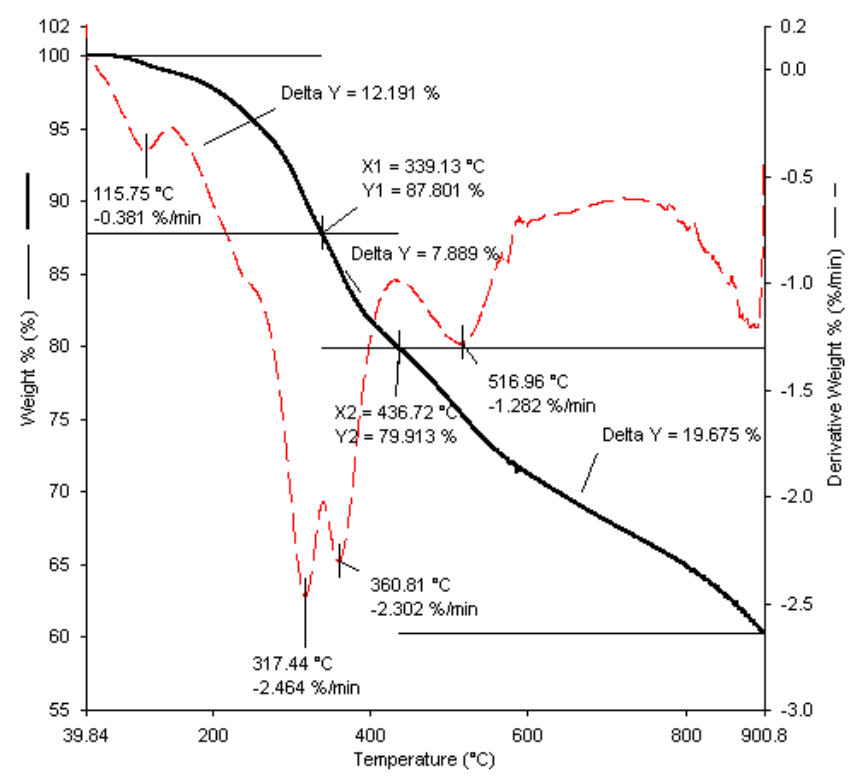

Figure 10. The TGA/DTA curve of RHAPrIM after the second used

\subsubsection{Characterization of azo dyes}

To give general applicability of RHAPrIM catalyst, various aromatic benzene derivatives were used to couple with the diazonium salt. Azo dyes derivatives were characterized by different techniques and the results listed in Table 3. Elemental analyses are clearly shown the abundant between the theoretical and found values Table 3 . The UV-Vis spectra (Figure 8) exhibit strong absorptions of $\pi-\pi^{*}$ transition for the azo moiety at wavelength $271,268,238,242,278$, and $273 \mathrm{~nm}$, respectively. The type of auxochrome groups on the azo derivatives are clearly affected on the absorptions. Red shifts were observed on those aromatic containing an electron-donating substituent. The FT-IR (not shown) is listed in Table 3. The effective bands are those due to the azo chromophore $(-\mathrm{N}=\mathrm{N}-)$, and other bands, e.g. $\mathrm{C}=\mathrm{C}$ and $\mathrm{C}-\mathrm{H}$ of the aromatic ring, and carbonyl were clearly shown on FT-IR spectra.

\subsection{Characterizations of the Reused Catalyst}

The FT-IR spectrum of RHAPrIM after the second reused is shown in Figure 9. All catalyst functional groups are shown at the expected position as compared to the fresh catalyst (Figure 3). The vibration of $\mathrm{Si}-\mathrm{O}-\mathrm{Si}$ is observed at $1068 \mathrm{~cm}^{-1}$ and to $1061 \mathrm{~cm}^{-1}$ in the fresh catalyst. Silanol groups and absorbed water appeared as a broadband around $3410 \mathrm{~cm}^{-1}$. This peak is becoming broader and slightly shifted as compared to the fresh catalyst as a result of the using the catalyst in water. The imidazole $\mathrm{C} 5-\mathrm{H}$ bond vibration has appeared at $3138-3110 \mathrm{~cm}^{-1}$. The vibration at $1562 \mathrm{~cm}^{-1}$ related to the benzene ring. Vibrations at 1647 $1626 \mathrm{~cm}^{-1}$ are due to the imine groups, $\mathrm{C}=\mathrm{N}$.

TGA/DTA curve of RHAPrIM after the second reused is shown in Figure 10. The sequence of characteristic decomposition stages is observed similar to the fresh catalyst (Figure 7). First mass loss of water adsorbed started at $39{ }^{\circ} \mathrm{C}$ with the maximum at $115{ }^{\circ} \mathrm{C}$ as in DTA curve. The amount of this mass loss becomes $12.1 \%$ as compared to the fresh one $(5.9 \%$, Figure 7). The rest mass losses are not changed too much as compared to the fresh catalyst.

\section{Conclusions}

Silica from RHA was transferred to sodium silicate followed by immobilizing with CPTES in a simple one-pot synthesis. The material resulted was treated with $\mathrm{p}$-xylyl di-imidazolium chloride to form a solid heterogeneous catalyst. Various spectroscopic methods were well char- 
acterized the catalyst such as elemental analysis, TGA/DTA, FT-IR and ${ }^{29}$ Si $\&^{13} \mathrm{C}$ MAS NMR spectra. The presence of $\mathrm{Q}^{4}, \mathrm{Q}^{3}, \mathrm{~T}^{3}$, and $\mathrm{T}^{2}$ silicon center in ${ }^{29} \mathrm{Si}$ MAS NMR and several peaks at a different position in ${ }^{13} \mathrm{C}$ MAS NMR spectrum are a good sign for silica modification with ligands. Thermal analysis shows that the catalyst can be used safely up to $277^{\circ} \mathrm{C}$. TEM images of RHAPrIM showed regularly shaped particles with an estimation size of ca. $5 \mathrm{~nm}$. Some particle seems to be smooth in shape, while the others show porous shape. The catalytic activity of RHAPrIM was examined insitu preparation of nitrous acid which was used to the prepared diazonium salt. The RHAPrIM was used to produces nitrous acid via its reaction with nitrite ions. Nitrous acid is the key start materials for dyes preparation via diazonium salt. Coupling reaction of aromatic compounds was carried out with a diazonium salt to yield a monoazo dye. All dyes were characterized by elemental analysis, IR, and UVVisible spectral studies. The catalyst was stable and reusable in short reaction times with a simple experimental procedure.

\section{Acknowledgement}

The Authors would like to thank AlMuthanna University, Republic of Iraq for financial support.

\section{References}

[1] Serafína, V., Torrente-Rodríguez, R.M., González-Cortésa, A., de Frutos, P.G., Sabaté, M., Campuzano, S., Yáñez-Sedeño, P., Pingarrón, J.M. (2018). An electrochemical immunosensor for brain natriuretic peptide prepared with screen-printed carbon electrodes nanostructured with gold nanoparticles grafted through aryl, diazonium salt chemistry. Talanta, 179: 131-138.

[2] Mammeri, F., Teyssandiera, J., DarcheDugaret, C., Debacker, S., Le Bourhis, E., Chehimi, M.M. (2014). Carbon nanotube-poly (methyl methacrylate) hybrid films: Preparation using diazonium salt chemistry and mechanical properties. J. Colloid Interface Sci., 433: 115-122.

[3] Wang, J., Li, S., Liang, R., Wu, B., He, Y. (2018). Synthesis and characterization of water-soluble PE Gylated lignin-based polymers by macromolecular azo coupling reaction. Chin. Chem. Lett., 29: 143-146.
[4] Fioresi, F., Vieillard, J., Bargougui, R., Bouazizi, N., Nkuigue, P., Emmanuel, F., Woumfo, D., Brunc, N., Mofaddel, N., Le Derf, F. (2017). Chemical modification of the cocoa shell surface using diazonium salts. $J$. Colloid Interface Sci., 494: 92-97.

[5] Son, Y.A., Park, Y.M., Shin, C.J., Kim, S.H. (2007). Self-assembly multi-layer of diazonium resin and its coupling reaction with $\mathrm{J}$-acid and H-acid. Dyes Pig.,72: 345-348.

[6] Dabbagh, H.A., Teimouri, A., Chermahini, A.N. (2007). Green and efficient diazotization and diazo coupling reactions on clays. Dyes Pig., 73: 239-244.

[7] Valizadeh, H., Amiri, M., Hosseinzadeh, F. (2012). Nanoparticles of organosilane-based nitrite ionic liquid immobilized on silica for the diazotization of aniline derivatives and subsequent synthesis of azo dyes. Dyes Pig., 92: 1308-1313.

[8] Adam, F., Osman, H., Hello, K.M. (2009). The immobilization of 3-(chloropropyl) triethoxysilane onto silica by a simple one-pot synthesis. J. Colloid Interface Sci., 331: 143-147.

[9] Salman, A.W., Ur Rehman, G., Abdullah, N., Budagumpi, S., Endud, S., Abdallah, H.H. (2015). Synthesis, characterization, density function theory and catalytic performances of palladium(II)- $N$-heterocyclic carbene complexes derived from benzimidazol-2-ylidenes. Inorg. Chim. Acta, 438:14-22.

[10] Yalçin, N., Sevinç, V. (2000). Studies on silica obtained from rice husk. Ceram. Int., 27: 219224.

[11] Brunaure, S., Deming, L.S., Deming, W.E., Teller, E. (1940). On a Theory of the van der Waals Adsorption of Gases. J. Am. Chem. Soc., 62: 1723-1732.

[12] Adam, F., Balakhrisnan, S., Wong, P.L. (2006). Rice husk ash silica as a support material for ruthenium based heterogenous catalyst. J. Phys. Sci., 17: 1-13.

[13] Hello, K.M. (2010). The heterogenation of saccharin, melamine, and sulfonic acid onto rice husk ash silica and their catalytic activity in esterification reaction. PhD Dissertation, School of Chemical Science, University Sains Malaysia, Malaysia. 